\title{
A Novel In Vitro System for Comparative Analyses of Bone Cells and Bacteria under Electrical Stimulation
}

\author{
Thomas Josef Dauben, ${ }^{1,2}$ Josefin Ziebart, ${ }^{1}$ Thomas Bender, ${ }^{1,2}$ Sarah Zaatreh, \\ Bernd Kreikemeyer, ${ }^{2}$ and Rainer Bader ${ }^{1}$ \\ ${ }^{1}$ Research Laboratory for Biomechanics and Implant Technology, Department of Orthopedics, Rostock University Medical Center, \\ 18057 Rostock, Germany \\ ${ }^{2}$ Institute of Medical Microbiology, Virology and Hygiene, Rostock University Medical Center, 18057 Rostock, Germany
}

Correspondence should be addressed to Rainer Bader; rainer.bader@med.uni-rostock.de

Received 25 May 2016; Revised 28 September 2016; Accepted 1 November 2016

Academic Editor: Mario U. Manto

Copyright (C) 2016 Thomas Josef Dauben et al. This is an open access article distributed under the Creative Commons Attribution License, which permits unrestricted use, distribution, and reproduction in any medium, provided the original work is properly cited.

\begin{abstract}
Electrical stimulation is a promising approach to enhance bone regeneration while having potential to inhibit bacterial growth. To investigate effects of alternating electric field stimulation on both human osteoblasts and bacteria, a novel in vitro system was designed. Electric field distribution was simulated numerically and proved by experimental validation. Cells were stimulated on Ti6Al4V electrodes and in short distance to electrodes. Bacterial growth was enumerated in supernatant and on the electrode surface and biofilm formation was quantified. Electrical stimulation modulated gene expression of osteoblastic differentiation markers in a voltage-dependent manner, resulting in significantly enhanced osteocalcin mRNA synthesis rate on electrodes after stimulation with $1.4 V_{\mathrm{RMS}}$. While collagen type I synthesis increased when stimulated with $0.2 V_{\mathrm{RMS}}$, it decreased after stimulation with $1.4 V_{\text {RMS }}$. Only slight and infrequent influence on bacterial growth was observed following stimulations with $0.2 V_{\text {RMS }}$ and $1.4 V_{\text {RMS }}$ after 48 and $72 \mathrm{~h}$, respectively. In summary this novel test system is applicable for extended in vitro studies concerning definition of appropriate stimulation parameters for bone cell growth and differentiation, bacterial growth suppression, and investigation of general effects of electrical stimulation.
\end{abstract}

\section{Introduction}

Over the past decades, electrical stimulation (ES) of various types of tissues has been established and gained importance for the treatment of a wide range of diseases and disabilities. Today, implants providing electrical stimulation are common in clinical use. They are applied in deep brain stimulation [1], as well as in cochlear implants [2] or, one of the most present examples, cardiac pacemakers [3]. Moreover, ES is a therapeutic approach for chronic cutaneous wound-healing complications [4], paralyzed muscles, or prevention of muscle atrophy in immobilized patients [5-7]. Further fields of application are pain relief therapy [8] and transcorneal ES after ocular trauma or for treatment of optic neuropathy and retina degeneration $[9,10]$. Another aspect with increasing importance is the use of ES or electromagnetic stimulation in the orthopedic field. Hereby, implants or devices applying ES are used as adjunctive therapy for treating bone fractures or supporting bone and tissue regeneration in cases of, for example, spinal cord injury, degenerative bone diseases, and pseudarthrosis [11-15]. Despite huge progress in the field of ES and promising results concerning ES of bone cells and other cell types, optimal stimulation methods and parameter combinations remain unclear. The effect and working mechanism of ES on bone cells have also to be elucidated in the future.

Furthermore, implant-associated infections of orthopedic implants are a major challenge for clinicians, present a huge burden for the affected patients and the associated healthcare systems, and are difficult to treat. Most often revision surgery is the only option $[16,17]$. The main bacterial causatives for implant-associated infections are staphylococci (i.e., Staphylococcus aureus and S. epidermidis). Both species are inhabitants of human skin and mucous membranes and are commonly found in hospital settings. These opportunistic human pathogens cause severe infections, mostly associated 
with biofilm formation on the implant surface [18]. Biofilm formation impairs successful treatment of infections since the bacteria are protected by extra-polymeric substances and a reduced metabolism, tremendously decreasing antibiotic susceptibility. Implant-associated infections usually lead to implant revision and broad tissue debridement as well as bone loss through inflammatory reactions. Several studies over the last years focused on ES of bacteria to prevent bacterial growth and biofilm formation [19-28]. Not only staphylococci but also Escherichia coli as well as Pseudomonas aeruginosa were investigated and tested using ES in different experimental set-ups [19-23]. Despite investigating and applying different types of electrical stimulation (e.g., direct current, alternating current, electromagnetic stimulation, or pulsed currents), the underlying effects of electrical stimulation, as well as effects on a more molecular level instead of macroscopic disruption of bacteria, still have to be elucidated. Several reactions can take place while using direct current, such as $\mathrm{pH}$ shifts, electrolytic reactions on the electrodes, temperature changes or formation of reactive oxygen species (ROS), $\mathrm{H}_{2} \mathrm{O}_{2}$, and chlorine production $[29,30]$. On the one hand, these effects can influence and impair bacterial growth and biofilm formation, while on the other hand challenging also bone cells or tissue. Alternating current, in a defined range of voltage, can exclude the before-mentioned side reactions and is therefore suited to solely investigate the influence of electric fields on bacteria. Although applying alternating current exhibits weaker inhibitory effects on bacteria compared to direct current stimulation, it is possible to reduce bacterial growth and biofilm formation using $\mathrm{AC}$ stimulation [29].

The ideal ES would enhance osteoblast recruitment to implant surface and surrounding and also lead to increased osteoblast differentiation, while protecting the implant surface from bacterial initial attachment, firm adherence, colonization, and biofilm establishment at the same time.

Since no electrical stimulation system is available enabling both stimulation of bone cells or other eukaryotic cells and bacteria, our goal was to generate an experimental tool for basic research on electrical stimulation. The generated system should allow testing of various stimulation conditions using bone cells and bacteria utilizing a broad range of applicable biological methods to maximize data output while being easily performed. In the study presented here, we introduce a new stimulation system and its experimental validation as well as first basic biological experiments. The system was tested on human primary osteoblasts (hOB) and $S$. epidermidis using two different voltages ( 0.2 and $\left.1.4 V_{\text {RMS }}\right)$ with a frequency of $20 \mathrm{~Hz}$ as basic conditions to prove general applicability.

\section{Material and Methods}

2.1. Electrical Stimulation Chamber. The stimulation chamber was built by rapid prototyping technology (IPT, Wismar, Germany) and is composed of Foto Med ${ }^{\circledR}$ LED.A material (Innovation MediTech GmbH, Unna, Germany). This material provides highly biocompatible properties that fulfill the

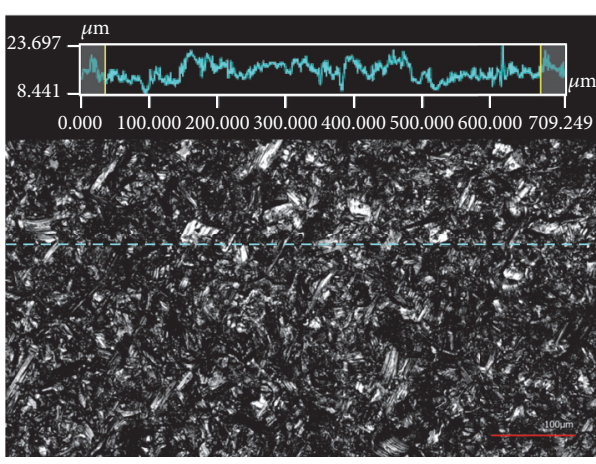

(a)

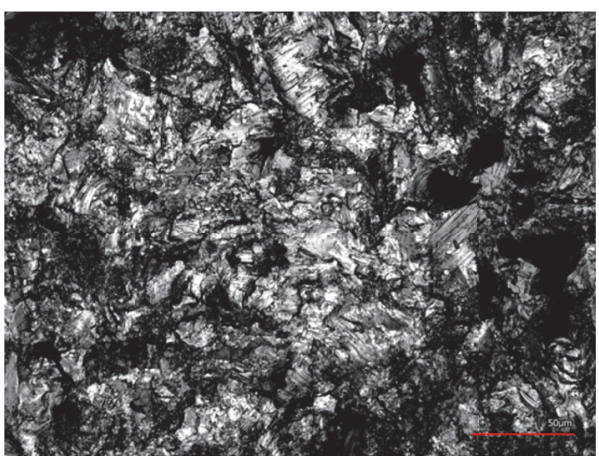

(b)

Figure 1: (a) Confocal 3D laser scanning image of the surface roughness measurement of corundum-blasted Ti6Al4V electrodes with 20x magnification. Dashed horizontal line shows the measured path with respective roughness values above. Red bar represents $100 \mu \mathrm{m}$. (b) 40x magnified image of the surface of a corundumblasted Ti6Al4V electrode. Red bar represents $50 \mu \mathrm{m}$.

guidelines of DIN ISO 10993. It is a nonconductive material which can be sterilized by autoclaving. Triangular electrodes (length: $23 \mathrm{~mm}$ ) with an equilateral base of $5 \times 5 \times 5 \mathrm{~mm}$ and contact rods were produced of Ti6Al4V by cutting (Primec, Bentwisch, Germany) and screwed together via threads. Electrodes were separated by an insulator of $5 \mathrm{~mm}$ width made of polyether ether ketone (PEEK) and were corundumblasted to a surface roughness of $21.38 \pm 4.67 \mu \mathrm{m}$, which was analyzed using the laser scanning microscope Keyence VK-X260 (Keyence Deutschland GmbH, Neu-Isenburg, Germany). Images of roughness measurement and electrode surface are presented in Figure 1. The three-dimensional CAD technical drawing as well as top view of the technical drawing including coordinate grid for validation are shown in Figures 2(a) and 2(b). Inner dimensions of the stimulation system are $54 \times 54 \times 26 \mathrm{~mm}$. Further components are a lid with holes for contact rods and an electrode holder shown in Figure 2(c). The distance between chamber bottom and electrodes was set to $5 \mathrm{~mm}$ according to the electric field simulation. The triangular shaped elecrodes seperated by an insulator are depicted in Figure 2(d).

2.2. Simulation and Validation of Electric Field Distribution. For the simulation, the finite element method (FEM) software 


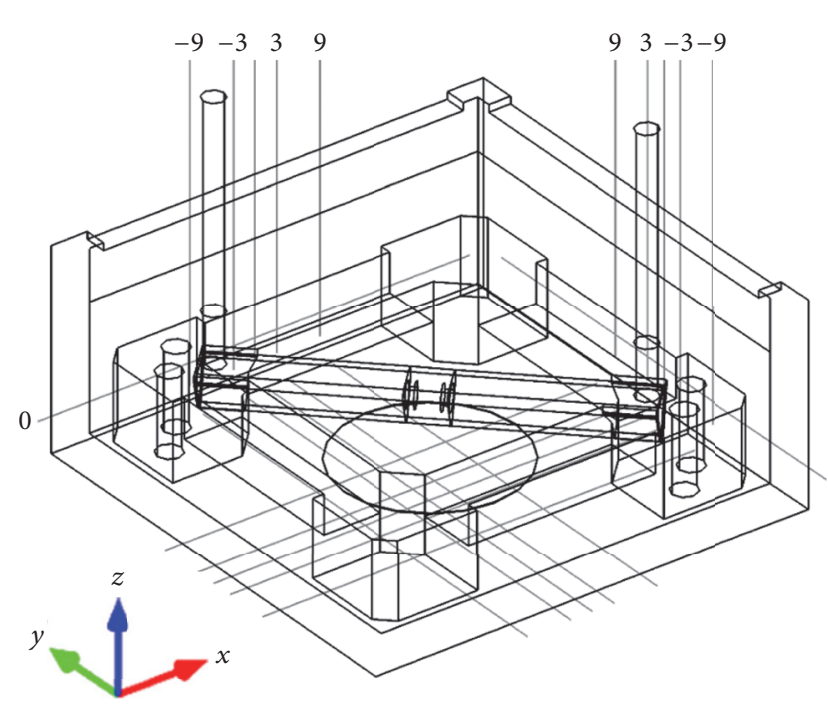

(a)

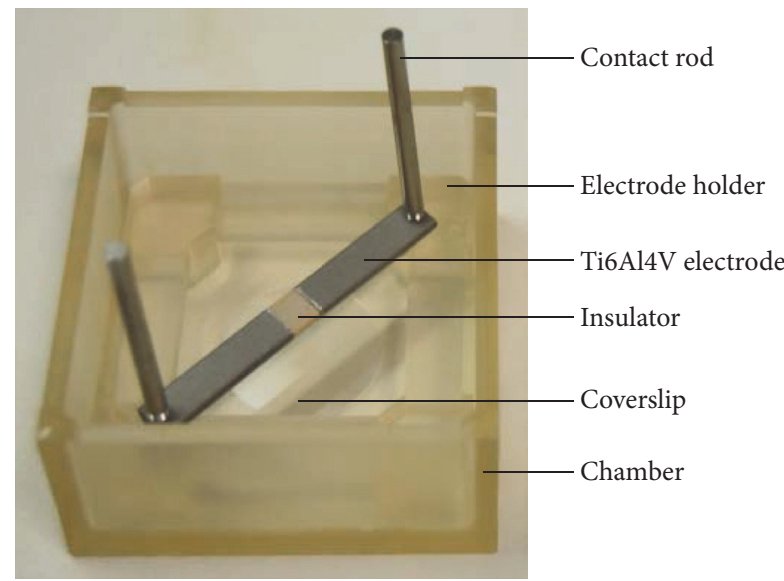

(c)

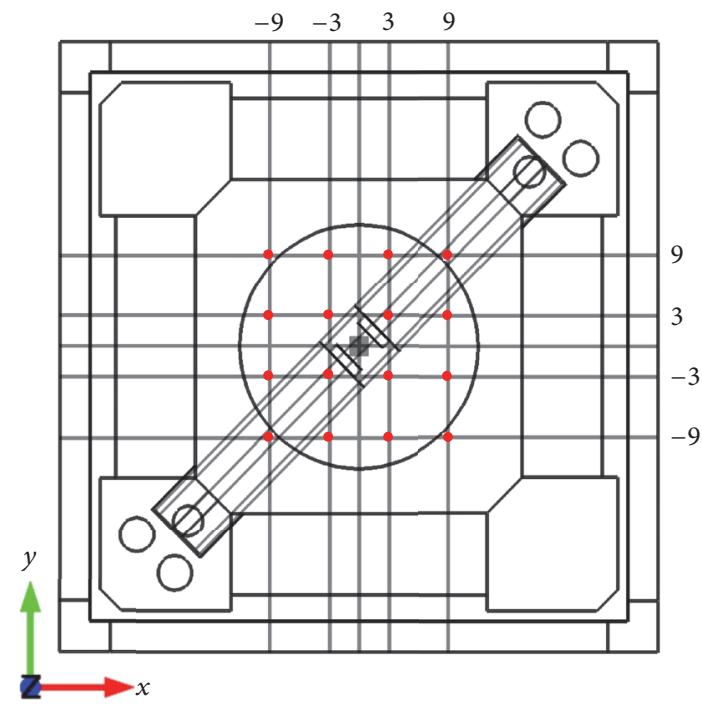

(b)

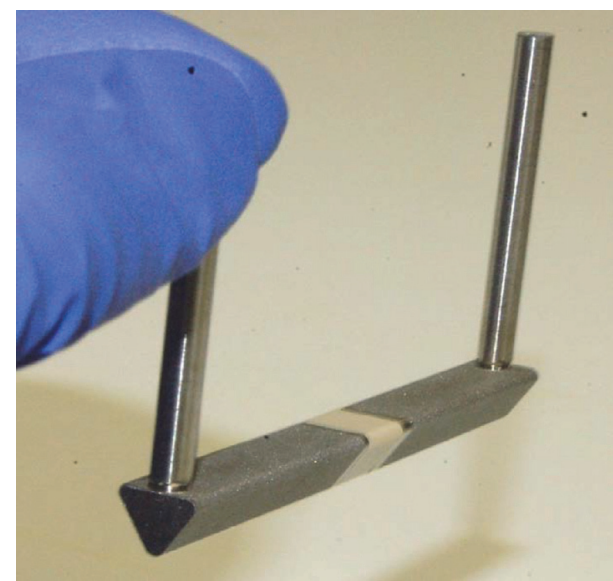

(d)

FIgURE 2: (a) Three-dimensional technical drawing of stimulation system including coordinate grid and round coverslip on bottom. (b) Top view technical drawing of stimulation system with coordinates. Red dots show coordinates where measurements for validation were done. (c) Composition of the electrical stimulation chamber. (d) Triangular electrodes with contact rods separated by insulator.

Comsol Multiphysics (Comsol Multiphysics 5.2, COMSOL, Stockholm, Sweden) was used to compute the electric field within the CAD model stimulation chamber. The assembly was based on the reconstruction of the electrical stimulation chamber, with electrodes and medium; therefore, Solidworks was used. Frequency-dependent medium and electrode electric properties were determined with impedance spectroscopy using a Broadband Dielectric Spectrometer (Novocontrol, Montabaur, Germany) and embedded in numerical simulations. In Comsol a Frequency Domain Study with a harmonic excitation of $20 \mathrm{~Hz}$ and an Electric Currents Physics Interface was created. The mesh was arranged as a free tetrahedral mesh and consisted of approximately 1.63 million mesh cells. To compare and validate the simulation of the electric field distribution with the in vitro situation, a simulation was performed using a root mean square (RMS) voltage of $1.35 \mathrm{~V}$. Used electrical properties of materials for numerical simulation are presented in Table 1. Potentials inside the chamber were measured as $V_{\mathrm{RMS}}$ using $20 \mathrm{~Hz}$ frequency, $1.35 V_{\text {RMS }}$ and DC-free sine wave. The measuring needle was a completely isolated stainless steel needle $(20 \mathrm{~mm}$ in length) with a conical tip of $0.4 \mathrm{~mm}$ diameter as contact surface. The measuring needle was grounded to one contact rod of the stimulation system and connected to an oscilloscope (TDS 2012B, Tektronix, Bracknell, Berkshire, UK). $V_{\mathrm{RMS}}$ measurements were done at defined coordinates in a $3 \mathrm{~mm}$ distance pattern plotted on the center of the chamber bottom according to the measurement grid (Figure 2(b)). $V_{\mathrm{RMS}}$ at the defined grid points were manually measured directly at the chamber bottom and measurements were repeated three times. To prevent external influence of the generated electric field, all technical devices except function generator and oscilloscope were switched off during the measurements. Measured $V_{\mathrm{RMS}}$ were then compared to RMS voltages given by numerical simulation. The validation set-up is shown in Figure 3. 
TABLE 1: Electric properties of materials and medium used for numerical simulation.

\begin{tabular}{lccc}
\hline Material & $\begin{array}{c}\text { Relative permittivity } \\
\varepsilon_{r}[1]\end{array}$ & $\begin{array}{c}\text { Electrical } \\
\text { conductivity } \sigma[\mathrm{S} / \mathrm{m}]\end{array}$ & Reference \\
\hline Air & 1 & 0 & $\begin{array}{c}\text { Comsol } \\
\text { (ideal) }\end{array}$ \\
Insulator & 4 & $1.00 E-11$ & $\begin{array}{c}\text { Comsol } \\
\text { (ideal) }\end{array}$ \\
Ti6A14V & 1 & $5,62 E+05$ & {$[31]$} \\
Medium & $1.08 E+08$ & $1.14 E+01$ & Measured \\
\hline
\end{tabular}

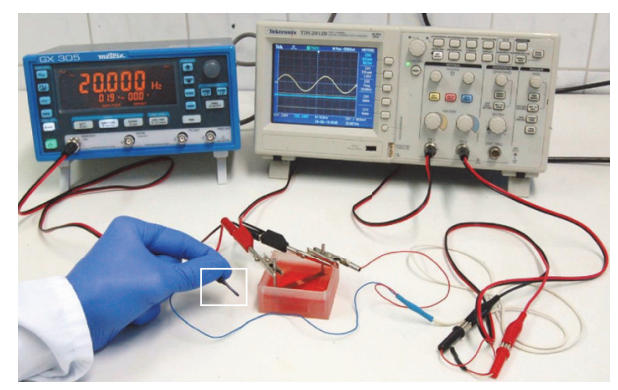

FIGURE 3: Representative image of the set-up for validation of electric potential distribution obtained from numerical simulations within the stimulation system. Electric potentials were measured with a pick-up electrode (white frame) connected to an oscilloscope.

2.3. Cell Experiments. Human primary osteoblasts were isolated from femoral heads of patients undergoing a primary total hip replacement under sterile conditions as previously described [32]. The samples were collected with consent of patients following approval by Local Ethical Committee (registration number: A 2010-10).

Isolated cells were cultured in Dulbecco's Modified Eagle Medium (DMEM) containing 10\% fetal calf serum (FCS), $1 \%$ amphotericin $\mathrm{B}, 1 \%$ penicillin-streptomycin, and $1 \%$ HEPESbuffer under standard cell culture conditions $\left(5 \% \mathrm{CO}_{2}\right.$ and $37^{\circ} \mathrm{C}$ ). Ascorbic acid (final concentration: $50 \mu \mathrm{g} / \mathrm{ml}$ ), $\beta$ glycerophosphate (final concentration: $10 \mathrm{mM}$ ), and dexamethasone (final concentration: $100 \mathrm{nM}$ ) were added to cell culture medium to promote osteogenic differentiation. For cell experiments, osteoblasts in passage three were seeded on coverslips with a diameter of $24 \mathrm{~mm}$ with a density of $2.2 \times 10^{4}$ cells $/ \mathrm{cm}^{2}$ and on electrodes with a density of $3.0 \times 10^{4}$ cells $/ \mathrm{cm}^{2}$. After adhering for $30 \mathrm{~min}, 30 \mathrm{ml}$ cell culture medium containing osteogenic additives was added, chambers were covered with the lid, and cells were incubated over night at $37^{\circ} \mathrm{C}$ under $5 \% \mathrm{CO}_{2}$ atmosphere.

Electrical stimulation started $12 \mathrm{~h}$ after cell seeding. 0.2 and $1.4 V_{\text {RMS }}$ with a frequency of $20 \mathrm{~Hz}$ were applied to the in vitro system using a Metrix GX 305 function generator (Metrix Electronics, Hampshire, UK) set to $20 \mathrm{~Hz}$. RMS voltage was directly measured and adjusted on the contact rods of the stimulation system. A sinusoidal signal was applied over three days with stimulation periods of $3 \times$ 45 min per day with 225 min break between stimulations. Cells were cultivated under standard cell culture conditions.
For unstimulated controls, chambers were similarly prepared without connection to the function generator. Cell viability and differentiation were investigated $12 \mathrm{~h}$ after the last stimulation period.

Water soluble tetrazolium (WST-1) assay (Cell Proliferation Reagent, Roche, Grenzach-Wyhlen, Germany) was used to measure metabolic activity of human osteoblasts. Cells were incubated with $700 \mu \mathrm{l}$ of WST-1 solution $(1: 10$ dilution in cell culture medium) for one hour. Absorbance was measured in triplicate at $450 \mathrm{~nm}$ (reference: $630 \mathrm{~nm}$ ) using an Opsys MR microplate reader (Dynex Technologies, Denkendorf, Germany). The LIVE/DEAD ${ }^{\odot}$ assay kit (Life Technologies, Carlsbad, USA) was used to discriminate between viable and dead cells. Live cells were stained by calcein-acetoxymethyl displaying intracellular esterase activity (green fluorescence, 494-517 nm). Dead cells were permeated by ethidium homodimer-1 red-fluorescent dye due to loss of membrane integrity (red fluorescence, 528$617 \mathrm{~nm}$ ). The assay was performed as recommended by the manufacturer. Images of the cells were taken with a fluorescence microscope (Nikon Type 120, Nikon Instruments, Tokyo, Japan) and evaluated using the NIS-Elements software (Nikon Instruments, Tokyo, Japan).

For gene expression analysis, osteoblasts were lysed in TriReagent ${ }^{\circledR}$ (Zymo Research Corporation, Irvine, CA, USA) and stored at $-70^{\circ} \mathrm{C}$ after stimulation experiments. Total RNA was extracted by using Direct-zol ${ }^{\mathrm{TM}}$ RNA MiniPrep Kit (Zymo Research Corporation, Irvine, CA, USA) according to manufacturer's instructions. 100 ng RNA were used for cDNA synthesis with the High Capacity cDNA Reverse Transcription Kits (Applied Biosystems, Carlsbad, CA, USA). Semiquantitative real-time PCR for collagen type 1 (Fwd: $5^{\prime}$ - ACGAAGACATCCCACCAATC -3', Rev: 5'-AGATCACGTCATCGCACAAC- $3^{\prime}$ ), alkaline phosphatase (Fwd: $5^{\prime}$-CATTGTGACCACCACGAGAG-3', Rev: $5^{\prime}$-CCATGATCACGTCAATGTCC- $3^{\prime}$ ), and osteocalcin (Fwd: $5^{\prime}$-GGTGCAGCCTTTGTGTCC-3', Rev: $5^{\prime}$-TCAGCCAACTCGTCACAGTC$3^{\prime}$ ) was performed in triplicate using innuMIX qPCR MasterMix SyGreen (Analytik Jena AG, Jena, Germany). Ct-values were normalized to the house-keeping gene hypoxanthine guanine phosphoribosyl transferase [33, 34] (HPRT, Fwd: $5^{\prime}$ CCCTGGCGTCGTGATTAGTG-3', Rev: 5' - TCGAGCAAGACGTTCAGTCC $-3^{\prime}$ ) and analysed by $2^{-\Delta \Delta c t}$ method.

The amount of procollagen type 1 was determined via ELISA (MicroVue ${ }^{\mathrm{TM}}$ CICP EIA, QUIDEL Corporation, San Diego, USA). This method detects the C-terminal propeptide of procollagen as a measure of collagen expression. Supernatants following ES were collected and stored at $-20^{\circ} \mathrm{C}$. Supernatants were then treated according to manufacturer's instructions and absorbance was measured at a wavelength of $405 \mathrm{~nm}$ using an Opsys MR microplate reader. A standard curve was used to determine protein content and measured values were related to respective controls.

2.4. Bacterial Experiments. All bacterial experiments were conducted with the catheter sepsis strain Staphylococcus epidermidis ATCC 35984. Bacteria were cultivated and passaged on Columbia blood agar plates (containing 3\% sheep blood) at least every 3 to 4 weeks. For long-term preservation, 
bacteria were stored at $-20^{\circ} \mathrm{C}$ in $50 \mu \mathrm{l}$ aliquots containing tryptic soy broth (TSB, AppliChem GmbH, Darmstadt, Germany) supplemented with $20 \%$ glycerin (v/v). For experiments, colony material from aliquots was transferred in $20 \mathrm{ml}$ TSB using an inoculation loop and incubated statically over night at $37^{\circ} \mathrm{C}$ under $5 \% \mathrm{CO}_{2}$ atmosphere.

Overnight cultures of $S$. epidermidis were centrifuged for $10 \mathrm{~min}$ at $3.345 \mathrm{~g}$, supernatants were discarded, and pellets were washed once with phosphate buffered saline (1x PBS, $\mathrm{pH}$ 7.4). In the following, pellets were suspended in fresh medium and optical density at $600 \mathrm{~nm}$ was adjusted to 0.35 matching approximately $10^{8}$ colony forming units per $\mathrm{ml}(\mathrm{CFU} / \mathrm{ml})$. Bacterial suspensions were subsequently diluted 100 -fold in fresh TSB and $30 \mathrm{ml}$ of bacterial suspensions containing $\sim 10^{6} \mathrm{CFU} / \mathrm{ml}$ were added to stimulation chambers.

Similar to the experiments with human osteoblasts, 0.2 and $1.4 V_{\mathrm{RMS}}$ were applied as sinusoidal signal at a frequency of $20 \mathrm{~Hz}$ using identical stimulation periods. The stimulation started $1 \mathrm{~h}$ after adding bacterial suspensions to the stimulation chambers. Constant voltage supply of desired 0.2 and $1.4 V_{\mathrm{RMS}}$, respectively, was monitored by sequential measurement during the stimulation periods using a digital multimeter (VC-960, Conrad Electronics, Hirschau, Germany). During the measurements conical stainless steel electrode tips of the digital multimeter were placed on top of the contact rods of the stimulation system and $V_{\mathrm{RMS}}$ was monitored. Samples of stimulated and unstimulated bacteria were collected following 24,48 , and $72 \mathrm{~h}$ of static incubation, respectively. Bacterial suspensions with similar concentrations added to chambers without electrical stimulation served as references for each time point. Both stimulated and nonstimulated samples were incubated at $37^{\circ} \mathrm{C}$ under $5 \%$ $\mathrm{CO}_{2}$ atmosphere.

For determination of $\mathrm{CFU} / \mathrm{ml}$, supernatants from control and stimulated samples were collected and stimulation chambers were washed twice with PBS to remove all nonadherent bacteria. Washing fractions and supernatants of corresponding samples were pooled and centrifuged for $10 \mathrm{~min}$ at $3.345 \mathrm{~g}$. Supernatants were discarded and pellets were suspended in 1x PBS. Serial dilutions were plated out on TSB agar plates and incubated overnight at $37^{\circ} \mathrm{C}$ under $5 \% \mathrm{CO}_{2}$ atmosphere. Respective $\mathrm{CFU} / \mathrm{ml}$ were determined on the following day.

For determination of $\mathrm{CFU} / \mathrm{ml}$ from the electrode surface, electrodes were removed from the stimulation system, rinsed two times with $1 \mathrm{x}$ PBS to remove nonadherent bacteria and subsequently transferred into glass tubes containing $1 \mathrm{x}$ PBS. Electrodes were ultrasonically agitated to remove all adherent bacteria. Suspensions containing former surfacebound $S$. epidermidis were centrifuged for $10 \mathrm{~min}$ at $3.345 \mathrm{~g}$, supernatants were discarded and pellets were suspended in 1x PBS. Serial dilutions were plated out on TSB agar plates and incubated overnight at $37^{\circ} \mathrm{C}$ under $5 \% \mathrm{CO}_{2}$ atmosphere. Respective $\mathrm{CFU} / \mathrm{ml}$ were determined on the following day.

To quantify biofilm mass, polystyrene coverslips (Nunc Thermanox $25 \mathrm{~mm}$ diameter, Thermo Fisher Scientific, Rochester, NY, USA) were removed from the chamber bottom and rinsed twice with $1 \mathrm{x}$ PBS. Biofilm mass was stained using $0.1 \% \mathrm{w} / \mathrm{v}$ crystal violet dissolved in Aqua dest. (Sigma-Aldrich, Steinheim, Germany) for $20 \mathrm{~min}$ at room temperature. Subsequently, coverslips were washed three times with Aqua dest. to remove excess crystal violet. Bound crystal violet was dissolved in $1 \%$ sodiumdodecylsulfate (SDS, Carl-Roth GmbH + Co.KG, Karlsruhe, Germany) for $20 \mathrm{~min}$ at $37^{\circ} \mathrm{C}$ with $350 \mathrm{rpm}$. Subsequently, absorption was measured at $590 \mathrm{~nm}$ against $1 \%$ SDS as blank. Measured values were further calculated regarding the surface area to determine formed biofilm mass $/ \mathrm{cm}^{2}$.

In order to determine antibiotic resistance, samples of supernatants were diluted in 1x PBS adjusting optical density to match approximately $10^{7} \mathrm{CFU} / \mathrm{ml}$. Cotton swab sticks were immersed for $10 \mathrm{~s}$ in the bacterial suspension and bacteria were subsequently spread out evenly on TSB agar plates. In the following, E-Test stripes of gentamicin and levofloxacin (BioMeriéux, France) were opposite aligned on the respective agar plates and plates were incubated overnight at $37^{\circ} \mathrm{C}$ under 5\% $\mathrm{CO}_{2}$ atmosphere. On the following day, minimal inhibitory concentrations (MIC $[\mu \mathrm{g} / \mathrm{ml}]$ ) of both antibiotics were determined resembling the highest concentration where bacteria at least reached the antibiotic stripe before inhibition zones appeared.

2.5. Data Illustration and Statistical Analysis. Data are presented as box plots and scatter dot plots. Boxes denote 10th90th percentile, horizontal lines within the boxes denote medians, and whiskers denote minimum and maximum values. Scatter dot plots show experimental values while horizontal lines within the plots denote medians. For all analyses, cultures of human osteoblasts from a minimum of three independent donors and of S. epidermidis from a minimum of four independent experiments were used. Since the data obtained were assumed to be not normally distributed, the statistical analyses were performed using Kruskal-Wallis Test followed by Dunn's Multiple Comparison Test to correct obtained $p$ values (embedded in GraphPad Prism 6.0). $p$ values less than 0.05 were considered statistically significant.

\section{Results}

3.1. Numerical Simulation on Electric Potential and Field Distribution in the Stimulation System. Numerical simulations of electric potential and electric displacement field norms are shown in Figure 4 while measured $V_{\text {RMS }}$ compared to simulated values are shown in Table 2. In general, the potential gradient predicted by numerical simulation was higher than in the stimulation system. Comparing the measured values of the four grid points between the two electrodes (coordinates $-9 / 9 ;-3 / 3 ; 3 /-3$; and $9 /-9$ ), the simulation shows a very good approximation of the real data with deviations of maximum $16 \mathrm{mV}$. However, in direction of both electrodes, the differences become higher resulting in maximum deviations of around $400 \mathrm{mV}$. When comparing measured versus simulation data, it can be clearly seen that the simulation anticipates a broader and more extensive gradient than it appears to be in the tested system. Measured values and simulation values showed the best approximation in the center of the region of interest. Here, the values were nearly identical. Figure 4(b) shows the electric displacement field 
TABLE 2: Measured and simulated electric potential of the measurement pattern of the stimulation system in the ROI.

\begin{tabular}{lccc}
\hline$x / y / z$ & $\begin{array}{c}\text { Measured } V_{\text {RMS }} \\
{[\mathrm{mm}]}\end{array}$ & $\begin{array}{c}\text { Simulated } V_{\text {RMS }} \\
\text { mean } \pm \mathrm{SD}[\mathrm{mV}]\end{array}$ & $\begin{array}{c}\mid \Delta V_{\text {simulated }}- \\
V_{\text {measured }} \mid[\mathrm{mV}]\end{array}$ \\
\hline$-9 / 9 / 0$ & $662 \pm 1$ & 655 & 7 \\
$-3 / 9 / 0$ & $716 \pm 7$ & 840 & 124 \\
$3 / 9 / 0$ & $773 \pm 10$ & 1072 & 299 \\
$9 / 9 / 0$ & $812 \pm 5$ & 1195 & 383 \\
$-9 / 3 / 0$ & $626 \pm 4$ & 470 & 156 \\
$-3 / 3 / 0$ & $668 \pm 9$ & 655 & 13 \\
$3 / 3 / 0$ & $728 \pm 10$ & 975 & 247 \\
$9 / 3 / 0$ & $763 \pm 6$ & 1072 & 309 \\
$-9 /-3 / 0$ & $583 \pm 2$ & 238 & 345 \\
$-3 /-3 / 0$ & $617 \pm 4$ & 335 & 282 \\
$3 /-3 / 0$ & $671 \pm 6$ & 655 & 16 \\
$9 /-3 / 0$ & $713 \pm 7$ & 840 & 127 \\
$-9 /-9 / 0$ & $540 \pm 1$ & 115 & 425 \\
$-3 /-9 / 0$ & $573 \pm 4$ & 238 & 335 \\
$3 /-9 / 0$ & $623 \pm 3$ & 470 & 153 \\
$9 /-9 / 0$ & $665 \pm 4$ & 655 & 10 \\
\hline
\end{tabular}

norm calculated with numerical simulation. The obtained field strength has its maximum in the ROI rising up top 80$90 \mathrm{~V} / \mathrm{m}$ while steadily decreasing with increasing distance from the center of the ROI.

3.2. Osteoblast Viability on Electrodes and Coverslips Is Not Affected by ES. Human primary osteoblasts cultivated on coverslips and titanium grade five electrodes were viable. Only single dead cells were visible in live/dead staining after three days of electrical stimulation with $0.2 V_{\mathrm{RMS}}$ (data not shown) or $1.4 V_{\mathrm{RMS}}$ as well as under control conditions (Figure 5(a)). Metabolic activity of osteoblasts measured by WST-1 assay was not altered after electrical stimulation compared to unstimulated cells for both cells growing on electrodes and coverslips (Figure 5(b)).

3.3. Gene Expression of Osteoblast Markers following ES. Gene expression analysis of primary osteoblasts cultured on titanium electrodes showed moderately higher transcript abundance of Col I, ALP, and OC after electrical stimulation with $0.2 V_{\text {RMS }}$ compared to unstimulated controls. Application of $1.4 V_{\text {RMS }}$ resulted in slightly enhanced OC transcript levels while Col I and ALP remained unchanged (Figure 6(a)). Osteoblasts growing on coverslips showed a tendency to increased Col I and ALP expression after application of $0.2 V_{\text {RMS }}$. Electrical stimulation with $1.4 V_{\text {RMS }}$ significantly increased OC transcript level $(p=0.0418)$ compared to cells treated with $0.2 V_{\mathrm{RMS}}$ (Figure 6(b)).

3.4. Collagen Type I Synthesis following ES with $1.4 V_{\mathrm{RMS}}$. Propeptide of procollagen type I in the supernatant of osteoblast cultures was detected by ELISA as a measure of newly produced collagen type I (Figure 7). Electrical stimulation with $0.2 V_{\mathrm{RMS}}$ significantly increased procollagen

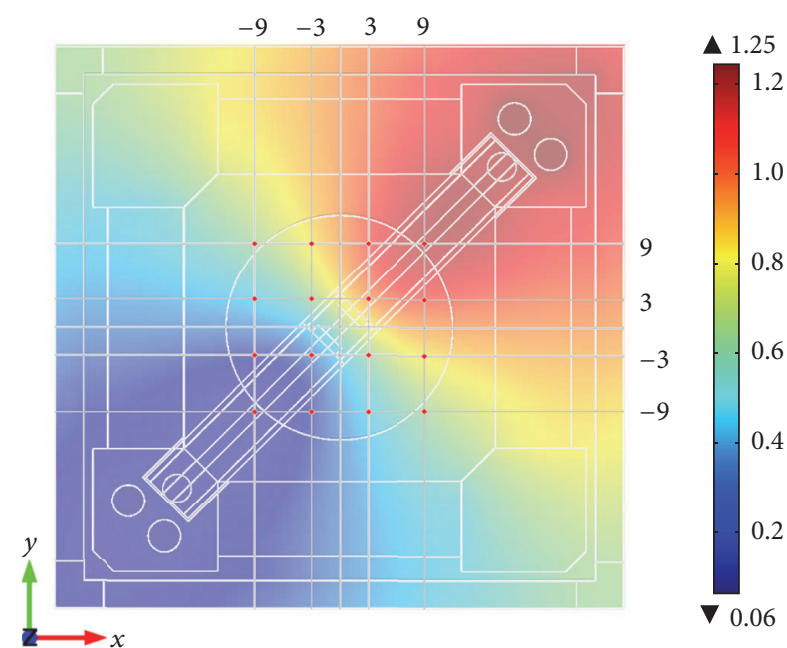

(a)

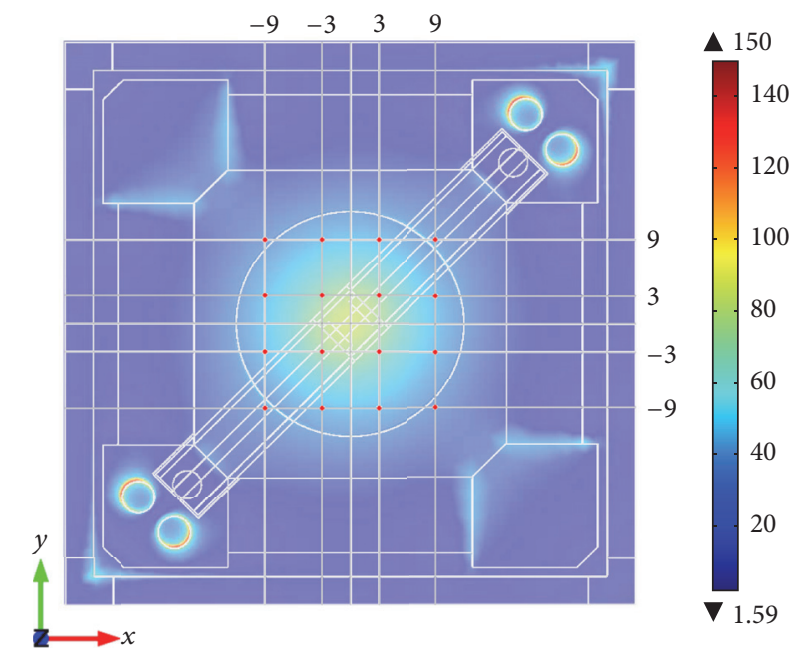

(b)

FIgURE 4: (a) Numerical simulation of electric potential in V. (b) Numerical simulation of electric displacement field norm in $\mathrm{V} / \mathrm{m}$ at the bottom of stimulation system. Red dots show coordinates where measurements for validation were done.

type I synthesis rate compared to osteoblasts treated with $1.4 V_{\mathrm{RMS}}(p=0.0051)$.

3.5. Determination of Bacterial CFU/ml in the Supernatant following ES. Determined CFU/ml of S. epidermidis from the supernatants of controls and stimulated samples are presented in Figure 8. Overall, $\mathrm{CFU} / \mathrm{ml}$ in the controls remained stable throughout the experiments and sampled time points. No differences between controls and either 0.2 or $1.4 V_{\text {RMS }}$ treated samples could be observed after $24 \mathrm{~h}$ of incubation. Following $48 \mathrm{~h}$, controls and $1.4 V_{\mathrm{RMS}}$ treated samples showed no differences, while $0.2 V_{\text {RMS }}$ treated samples showed significantly reduced CFU/ml $(p=0.0355)$. Following $72 \mathrm{~h}$ of incubation, significantly decreased $\mathrm{CFU} / \mathrm{ml}$ were observed for $1.4 V_{\text {RMS }}$ treated samples compared to controls $(p=$ 0.0142 ). Differences between controls and $0.2 V_{\text {RMS }}$ treated bacteria were not significant at this time point. 

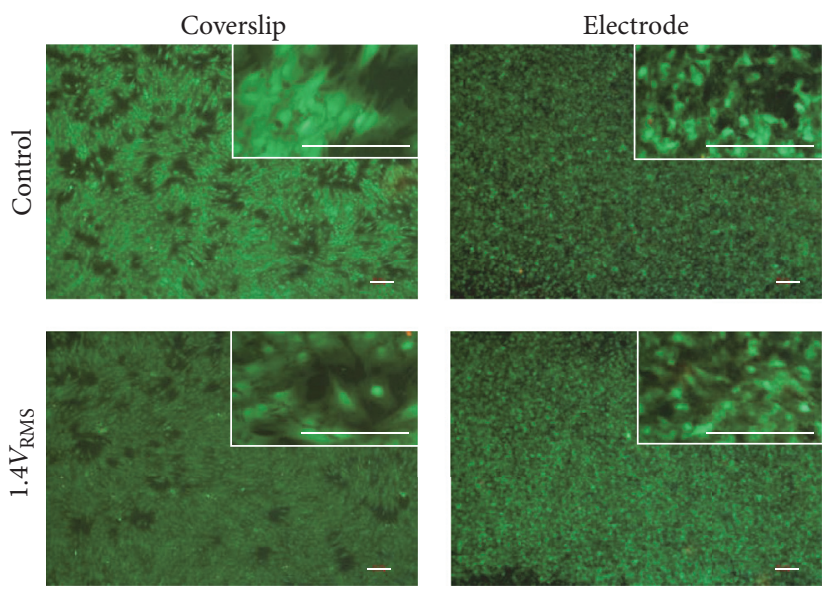

(a)

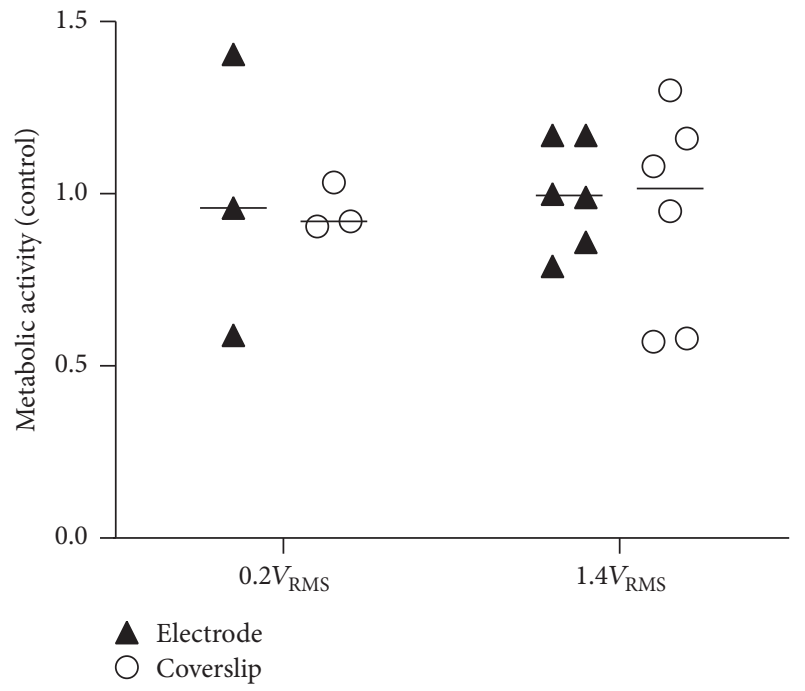

(b)

FIGURE 5: (a) Live/dead staining of human osteoblasts on coverslips and titanium electrode after three days of electrical stimulation with $1.4 V_{\text {RMS }}$ and under control conditions. Live cells display green fluorescence. Dead cells appear red. White bars represent $100 \mu \mathrm{m}$. (b) Metabolic activity of human osteoblasts on titanium electrode and coverslips after three days of electrical stimulation with $0.2 V_{\text {RMS }}$ or $1.4 V_{\mathrm{RMS}}$ compared to controls. Values are presented as median and single values. $n \geq 3$.

3.6. Determination of Bacterial CFU/ml on the Electrode Surface following ES. The range of S. epidermidis CFU/ml recovered from the electrode surface of controls remained relatively stable throughout the experiment (Figure 9). Following $24 \mathrm{~h}$ of incubation, no differences were observed comparing controls and $1.4 V_{\mathrm{RMS}}$ treated samples. After 48 and $72 \mathrm{~h}$ of incubation, $1.4 V_{\mathrm{RMS}}$ treated samples showed slightly lower $\mathrm{CFU} / \mathrm{ml}$ compared to controls. In general, lower $\mathrm{CFU} / \mathrm{ml}$ of $0.2 V_{\mathrm{RMS}}$ treated samples were detected compared to controls at all time points. These differences did not obtain significance levels.

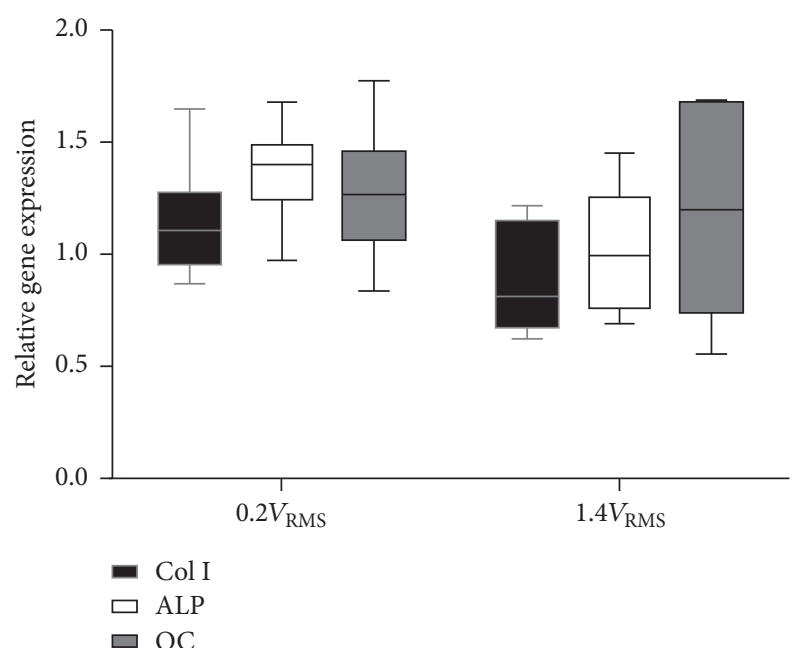

(a)

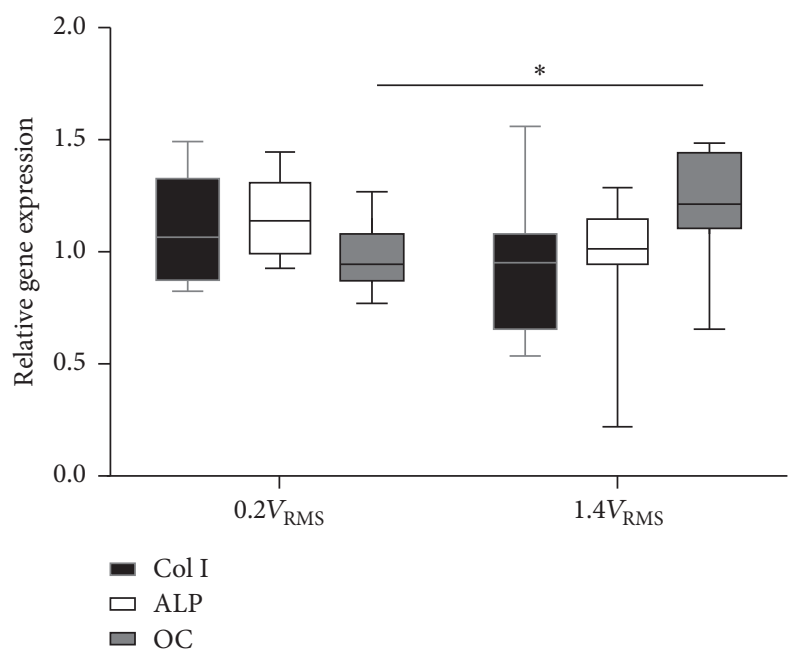

(b)

FIGURE 6: Relative gene expression of human osteoblasts on titanium electrode (a) and coverslips (b) after three days of electrical stimulation with $0.2 V_{\mathrm{RMS}}$ or $1.4 V_{\mathrm{RMS}}$ compared to controls. Values are presented as boxplots, while whiskers denote minimum and maximum. $n \geq 6 .{ }^{*} p<0.05$ (Kruskal-Wallis Test followed by Dunn's Multiple Comparison Test). Col I: collagen type I, ALP: alkaline phosphatase, OC: osteocalcin.

3.7. Determination of S. epidermidis Biofilm Mass Formation following ES. Biofilm mass decreased during the experiment in controls and stimulated samples (Figure 10). Comparing all tested conditions, highest biofilm mass was detected following $24 \mathrm{~h}$ of incubation. No significant differences could be observed between controls and both stimulated samples, while all samples showed a high variance in biofilm mass formation. Following 48 and $72 \mathrm{~h}$ of incubation, biofilm mass decreased compared to $24 \mathrm{~h}$ of incubation but remained stable during 48 and $72 \mathrm{~h}$. No differences could be observed comparing controls and stimulated samples, regardless of the stimulation conditions. 


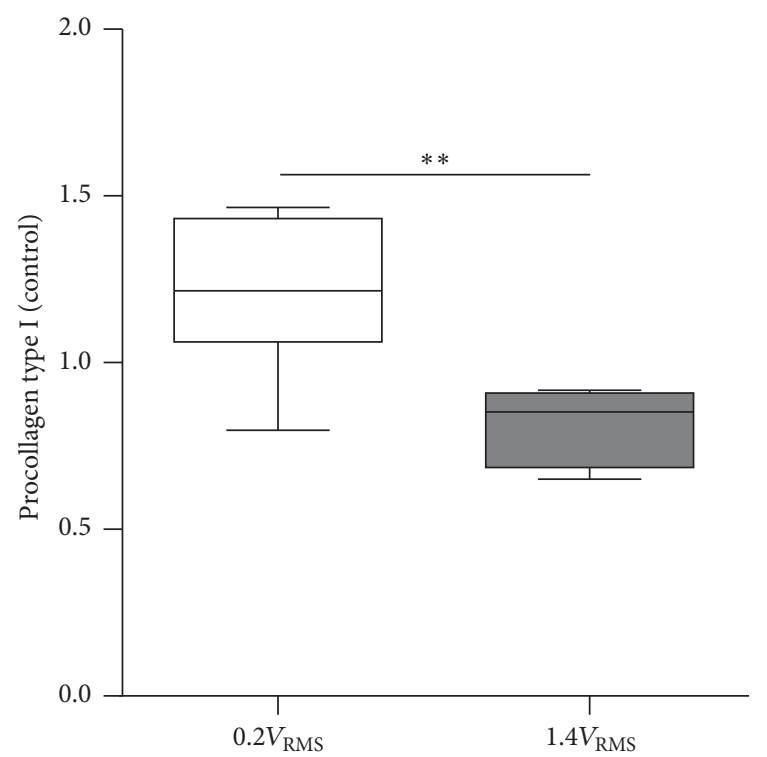

FIGURE 7: Procollagen type I in supernatant of human osteoblasts cultures after three days of electrical stimulation with $0.2 V_{\text {RMS }}$ or $1.4 V_{\mathrm{RMS}}$ compared to controls. Values are presented as boxplots, while whiskers denote minimum and maximum. $n \geq 5,{ }^{* *} p<0.01$ (Kruskal-Wallis Test followed by Dunn's Multiple Comparison Test).

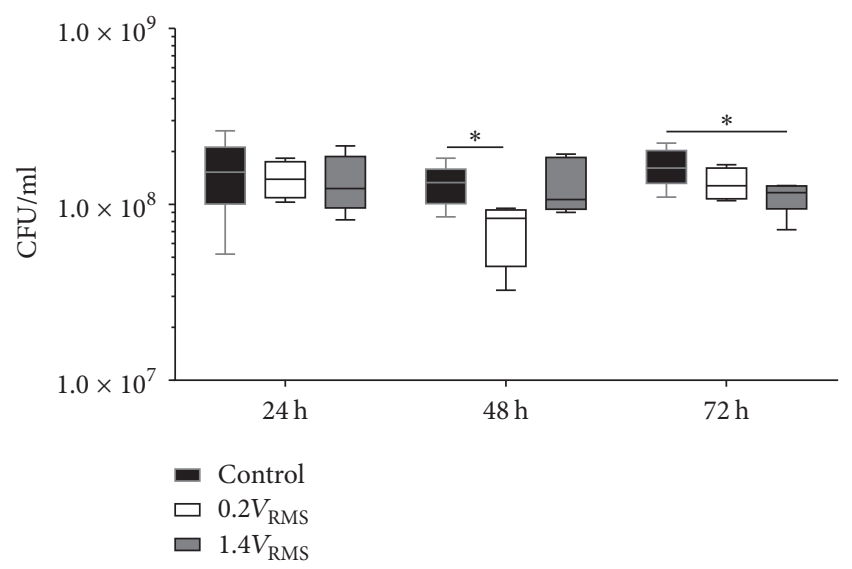

FIGURE 8: CFU/ml of planktonic S. epidermidis from the supernatant of controls and with $0.2 V_{\text {RMS }}$ and $1.4 V_{\text {RMS }}$ treated samples over $72 \mathrm{~h}$. Values are presented as boxplots, while whiskers denote minimum and maximum. $n \geq 4 .{ }^{*} p<0.05$ (Kruskal-Wallis Test followed by Dunn's Multiple Comparison Test).

3.8. Antibiotic Susceptibility following ES. In general, variations in MICs of gentamicin were high during the experiments (Figure 11(a)) and ranged for controls and $1.4 V_{\mathrm{RMS}}$ treated samples between 12 and $64 \mu \mathrm{g} / \mathrm{ml}$ and between 12 and $50 \mu \mathrm{g} / \mathrm{ml}$ for $0.2 V_{\text {RMS }}$ treated samples, respectively. These high variations are due to the E-Test assay and the gentamicin resistance of $S$. epidermidis, which was previously determined. $0.2 V_{\text {RMS }}$ treated samples showed a tendency to result in lower MICs compared to control samples at all time points, while $1.4 V_{\mathrm{RMS}}$ treated samples showed no differences compared to control samples. S. epidermidis was

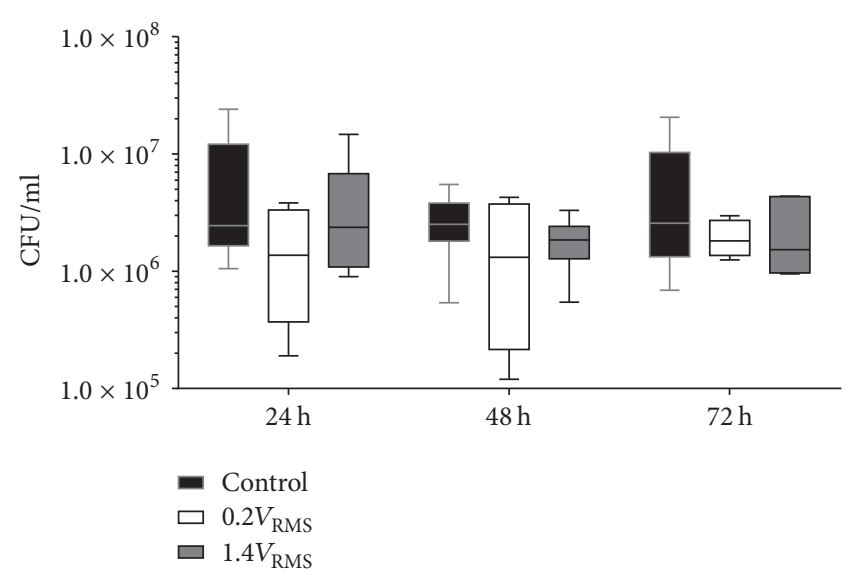

FIGURE 9: CFU/ml of adherent $S$. epidermidis from the electrode surface of controls and with $0.2 V_{\mathrm{RMS}}$ and $1.4 V_{\mathrm{RMS}}$ treated samples over $72 \mathrm{~h}$. Values are presented as boxplots, while whiskers denote minimum and maximum. $n \geq 4$.

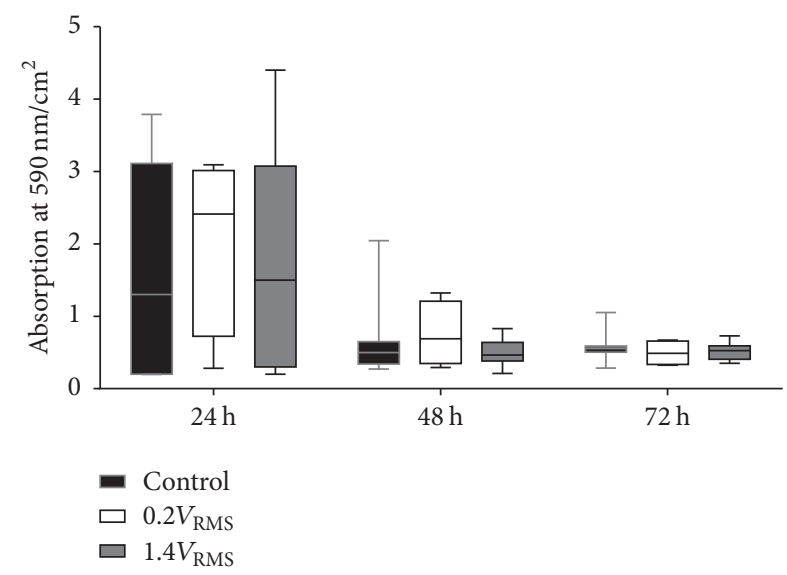

FIGURE 10: Biofilm mass quantification via crystal violet staining of S. epidermidis formed biofilm in relation to the surface area of the coverslip of controls and with $0.2 V_{\text {RMS }}$ and $1.4 V_{\text {RMS }}$ treated samples over $72 \mathrm{~h}$. Values are presented as boxplots, while whiskers denote minimum and maximum. $n \geq 4$.

previously tested sensitive against levofloxacin. Therefore, MICs were essentially lower compared to MICs determined for gentamicin and ranged between 0.032 and $0.094 \mu \mathrm{g} / \mathrm{ml}$ (Figure 11(b)). During experiments no changes in antibiotic susceptibility against levofloxacin could be observed under all tested conditions.

\section{Discussion}

In the present study a novel electrical stimulation system was developed and functionally validated in order to create a test system allowing single and simultaneous ES of human cells and bacteria. The simulation data approximate the measured real data in case of electric potential distribution in the region of interest and give the opportunity to calculate the electric field distribution of varying parameter combinations. Furthermore, general applicability for stimulating bone cells 


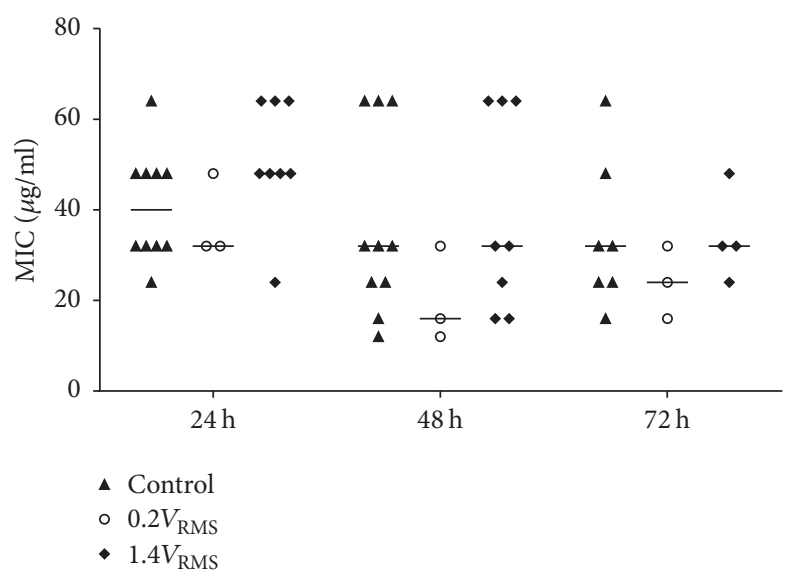

(a)

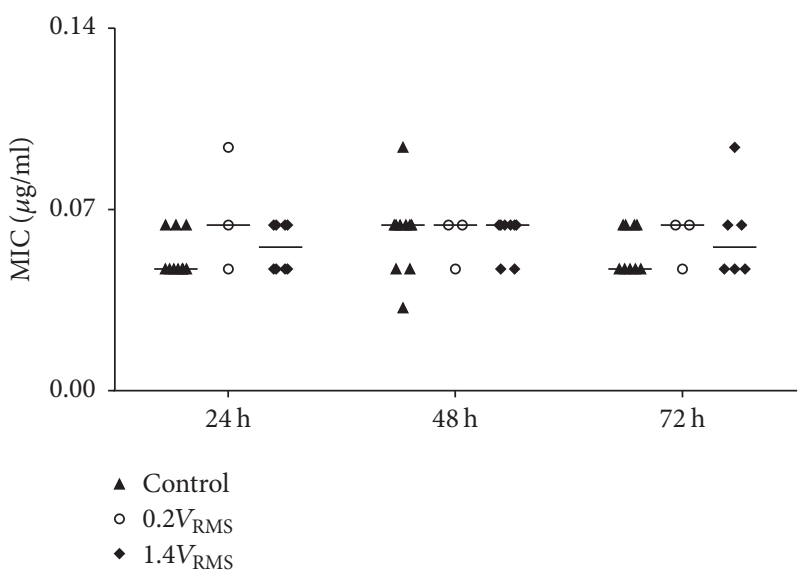

(b)

FIGURE 11: Determined minimal inhibitory concentrations (MIC) of gentamicin (a) and levofloxacin (b) using $E$-Test stripes with samples of the supernatants of controls and with $0.2 V_{\mathrm{RMS}}$ and $1.4 V_{\mathrm{RMS}}$ treated samples over $72 \mathrm{~h}$. Values are presented as median and single values. $n \geq 3$.

as well as bacteria was proven. When developing a system for ES application, whether for future clinical use or to test effects on different eukaryotic cells and bacteria, it is important to characterize and validate the stimulation system. Using direct current, electrochemical reactions have to be considered like $\mathrm{pH}$ shifts and hydrogen peroxide formation, but also the formation of chlorine molecules and radicals as well as ROS, which can damage the host tissue [29]. We applied alternating current to circumvent the mentioned indirect effects occurring through DC application and solely investigate effects of electric fields on cells and bacteria. The electric field distribution and field strengths are strongly influenced by the electrode shape, the materials used for the electrode, the surrounding medium and the type of electrical stimulation. Therefore, we integrated the CAD model as well as material- and medium-specific electrical properties into the finite element simulation and validated the simulation by measuring electric potentials in the area of interest where cells and bacteria were analyzed in subsequent experiments. The simulated electric displacement field obtained from simulation anticipated field strengths of 5 up to around $90 \mathrm{~V} / \mathrm{m}$ in the middle of the region of interest. However, the validation experiment showed that the electric potential gradient inside the stimulation system is considerably smaller compared to the simulation. This shows that the highest field strengths of the simulation are not likely to be reached in the stimulation system. Additionally, a smaller potential gradient means a more homogeneous field distribution than assumed by numerical simulation. Hence, bone cells and bacteria in the whole ROI are influenced by similar electric field strengths. The triangular shaped electrode was chosen to allow cell seeding directly on the electrode surface. Starting parameters for electrical stimulation as well as stimulation periods were adopted from the clinically used ASNIS III sseries screw system, a clinical set-up providing magnetic field stimulation with an additional alternating electric field up to $70 \mathrm{~V} / \mathrm{m}$ in case of bone fractures, avascular necrosis of the femoral head, or foot arthrodesis $[35,36]$. Both $0.2 V_{\mathrm{RMS}}$ and $1.4 V_{\mathrm{RMS}}$ were chosen to cover minimum and maximum electric field strengths created by the ASNIS set-up. Our system enables investigation of the effect of alternating electric fields on human osteoblasts and bacteria adhering to the surface of an implant material providing electrical stimulation as well as on a coverslip in distance to the electrodes. Further, planktonic bacterial growth under electric field exposure can be examined. Suggesting future clinical application, permanent implants like joint endoprostheses or dental implants, integrating devices or components enabling electrical stimulation, may be used to prevent aseptic loosening by enhancing osseointegration of implants.

Ti6Al4V alloys are, apart from cobalt-chromium alloys, broadly used as material for total joint endoprostheses [37, 38] providing excellent biocompatibility and a high fatigue limit as well as low Young's modulus and density [37, 39, 40]. Furthermore, Ti6Al4V provides high corrosion resistance due to formation of a passivation layer [41]. Therefore, we chose Ti6Al4V as it is still considered the most important titanium alloy for joint endoprostheses. Human osteoblasts were viable when cultured on titanium electrodes and in small distance to the electrodes on chamber bottoms. Viability as well as metabolic activity was maintained after three days of ES proving biocompatibility of the chamber and electrode material as well as excluding harmful effects of applied voltage or negative electrode reactions. Electrodes were roughened by corundum blasting gaining a roughness $R z$ of about $23 \mu \mathrm{m}$. Rough titanium surfaces on implants enlarge the implant surface and thereby contribute to primary implant stability. Furthermore, rough surfaces were shown to enhance osseointegration by promotion of osseoconduction characterized by protein adsorption and cell adhesion to the implant surface which leads to the formation of a fibrin matrix and directs osseoinduction [42-45]. In vitro rough surfaces enhanced synthesis of growth factor and extracellular matrix synthesis in osteoblasts [46-48].

Several previous studies published in the past years worked with varying electrical stimulation set-ups, stimulation parameters, and different investigated cell types. Using the presented stimulation chamber gene expression of the distinct osteogenic differentiation markers collagen 
type I and alkaline phosphatase were moderately increased following ES with $0.2 V_{\mathrm{RMS}}$, while osteocalcin expression was enhanced after applying $1.4 V_{\mathrm{RMS}}$ indicating voltagedependent alteration of osteoblast differentiation. Analysis of collagen type I synthesis on protein level confirmed voltagedependent effects of ES. While lower voltage increased Col I synthesis, higher voltage decreased extracellular matrix production. Modulation of bone cell marker expression by electromagnetic field exposure has been shown previously. Investigation of osteoblastic differentiation of mesenchymal stem cells under stimulation with alternating current electric fields using $2 \mathrm{~V} / \mathrm{m}$ and $60 \mathrm{kHz}$ showed enhanced synthesis rates of collagen type I and alkaline phosphatase mRNA after 15 days of electrical stimulation ( $40 \mathrm{~min}$ per day) whereas collagen fiber deposition and calcium nodule formation were similar between control and stimulation group [49]. Others stimulated rat calvarial osteoblasts on current-conducting nanocomposites $(10 \mu \mathrm{A}, 10 \mathrm{~Hz}$, and $6 \mathrm{~h}$ per day) resulting in enhanced proliferation after two days and increased synthesis of collagenous and noncollagenous proteins as well as elevated calcium content after 21 days [34]. Ercan and Webster stimulated osteoblasts cultured on nanotubular titanium with pulsed electric fields (1-15 V, pulse duration: $0.4 \mathrm{~ms}, 1 \mathrm{~h}$ per day) [50]. Osteoblasts showed highest proliferation after stimulation with $10 \mathrm{~V}$ after five days. Furthermore, nanotubular structures stimulated alkaline phosphatase activity and calcium deposition in osteoblasts synergistically with electric stimulation in long-term experiments. Gittens et al. stimulated the osteoblast-like cell line MG-63 with $0.1-0.5 \mathrm{~V}$ for two hours by direct polarization of titanium discs which served as cell culture substrate [51]. They observed decreased proliferation and enhanced expression of osteoblast proteins osteoprotegerin and osteocalcin and vascular endothelial growth factor (VEGF). Effects were higher when titanium discs were connected to the cathode rather than connected to the anode. In a previous in vitro study we applied magnetically induced alternating electric fields of $0.7 \mathrm{~V}(20 \mathrm{~Hz}$, $3 \mathrm{mT}, 3 \times 45 \mathrm{~min}$ per day) to human osteoblasts embedded in an agarose matrix [52]. Electromagnetic stimulation significantly enhanced alkaline phosphatase and osteocalcin mRNA levels and elevated protein synthesis of collagen type I. Since we could show contribution of collagen, which displays piezoelectric properties, to the positive outcome of electrical stimulation when human osteoblasts were stimulated on collagen-composing scaffolds [36], collagen-coated glass coverslips are used in ongoing experiments.

Experiments with S. epidermidis under conditions similar to osteoblast experiments showed slightly inhibitory effects after AC application as well. Even ES with low AC voltage decreased CFU/ml of bacteria in the supernatant as well as on the electrode surface. Though effects of AC stimulation resulted in statistically significant decreased $\mathrm{CFU} / \mathrm{ml}$ in the supernatants when stimulating $S$. epidermidis with 0.2 and $1.4 V_{\mathrm{RMS}}$, respectively, these observations were not constant over time. Reductions in $\mathrm{CFU} / \mathrm{ml}$ to the observed extent would only slightly slow down bacterial growth. However, it is notable that the low $V_{\text {RMS }}$ used in the present work affected bacterial growth. These results are in line with other AC studies reporting growth inhibition and bactericidal effects, though to a lower extent compared to most DC experiments [29]. Moreover, we can exclude promotion of S. epidermidis growth and adherence to the implant material by the ES parameters used in this study. Different mechanisms for inhibitory effects of ES on bacteria are discussed (e.g., $\mathrm{pH}$ changes as well as electrochemical reactions leading to $\mathrm{H}_{2} \mathrm{O}_{2}$, ROS, or chlorine molecules). Sandvik et al. [30] showed that the amount of chlorine formed during DC stimulation influences bactericidal efficacy. When chlorine was added in the same amount as formed during their experiments, while no DC stimulation was applied, similar reductions of living bacteria were observed. In our study, neither $\mathrm{pH}$ differences (data not shown) nor $\mathrm{H}_{2} \mathrm{O}_{2}$ formation could be observed in $1.4 V_{\mathrm{RMS}}$ stimulated samples compared to controls. Hence, underlying mechanisms for observed inhibitory effects on bacteria have to be elucidated.

The successful construction and establishment of our new stimulation system enable cellular and bacterial experiments under defined conditions, allowing investigation of ES effects. Ti6Al4V electrodes can be exchanged easily so that electrodes made of various implant alloys with desired surface properties can be investigated. Further implementation of bone substitute materials (i.e., scaffolds for bone cell settlement) is possible at the chamber bottom to approach more physiologic growth conditions. Subsequent studies will focus on effects on bacterial growth and biofilm formation as well as bone cells under extended AC stimulation conditions. Additionally, coculture experiments will be performed to determine effects of electrical stimulation on the interaction of bone cells and bacteria. However, results need to be verified in living organisms and carefully prepared clinical studies.

\section{Conclusion}

Our test system enables experiments applying electrical stimulation on eukaryotic cells and bacteria under similar conditions in a simplified system. Only slight effects on bone cells and bacteria could be observed using two different parameter combinations. However, the established methodical set-up allows high data output based on the experimental question (i.e., planktonic bacteria, formed biofilm, and behavior of eukaryotic cells and bacteria on the electrode/implant surface and in electrode surrounding). Thus, this system is suitable for in vitro investigations regarding effects of electrical stimulation on bacteria and cells and their potential clinical relevance. It is valuable for basic research on variation of stimulation conditions and parameters by presenting a simplified system that enables a broad methodical range.

\section{Competing Interests}

The authors declare no conflict of interests. The authors alone are responsible for the content and writing of the paper.

\section{Authors' Contributions}

Thomas Josef Dauben and Josefin Ziebart contributed equally to the work. 


\section{Acknowledgments}

This work was financially supported by the German Research Foundation (DFG) via the GRK 1501 Welisa. The authors would like to thank Dr. Andreas Wurm and Dr. Heiko Huth from the Institute of Physics, University of Rostock, for assistance with impedance spectroscopy.

\section{References}

[1] J. S. Perlmutter and J. W. Mink, "Deep brain stimulation," Annual Review of Neuroscience, vol. 29, pp. 229-257, 2006.

[2] F.-G. Zeng and R. R. Fay, Eds., Cochlear Implants: Auditory Prostheses and Electric Hearing, vol. 20, Springer Science \& Business Media, 2013.

[3] P. J. Bradshaw, P. Stobie, M. W. Knuiman, T. G. Briffa, and M. S. Hobbs, "Trends in the incidence and prevalence of cardiac pacemaker insertions in an ageing population," Open Heart, vol. 1, no. 1, article e000177, 2014.

[4] L. C. Kloth, "Electrical stimulation for wound healing: a review of evidence from in vitro studies, animal experiments, and clinical trials," International Journal of Lower Extremity Wounds, vol. 4, no. 1, pp. 23-44, 2005.

[5] A. K. Vafadar, J. N. Côté, and P. S. Archambault, "Effectiveness of functional electrical stimulation in improving clinical outcomes in the upper arm following stroke: a systematic review and meta-analysis," BioMed Research International, vol. 2015, Article ID 729768, 14 pages, 2015.

[6] E. Zanotti, G. Felicetti, M. Maini, and C. Fracchia, "Peripheral muscle strength training in bed-bound patients with COPD receiving mechanical ventilation: effect of electrical stimulation," Chest, vol. 124, no. 1, pp. 292-296, 2003.

[7] H. Kern, S. Salmons, W. Mayr, K. Rossini, and U. Carraro, "Recovery of long-term denervated human muscles induced by electrical stimulation," Muscle \& Nerve, vol. 31, no. 1, pp. 98-101, 2005.

[8] D. N. Rushton, "Electrical stimulation in the treatment of pain," Disability and Rehabilitation, vol. 24, no. 8, pp. 407-415, 2002.

[9] L. Fu, A. C. Y. Lo, J. S. M. Lai, and K. C. Shih, "The role of electrical stimulation therapy in ophthalmic diseases," Graefe's Archive for Clinical and Experimental Ophthalmology, vol. 253, no. 2, pp. 171-176, 2015.

[10] A. Schatz, T. Röck, L. Naycheva et al., "Transcorneal electrical stimulation for patients with retinitis pigmentosa: a prospective, randomized, sham-controlled exploratory study," Investigative Ophthalmology \& Visual Science, vol. 52, no. 7, pp. 4485-4496, 2011.

[11] J. D. Dolbow, D. R. Dolbow, A. S. Gorgey, R. A. Adler, and D. R. Gater, "The effects of aging and electrical stimulation exercise on bone after spinal cord injury," Aging and Disease, vol. 4, no. 3, pp. 141-153, 2014.

[12] C. L. Sadowsky, E. R. Hammond, A. B. Strohl et al., "Lower extremity functional electrical stimulation cycling promotes physical and functional recovery in chronic spinal cord injury," Journal of Spinal Cord Medicine, vol. 36, no. 6, pp. 623-631, 2013.

[13] K. Kohata, S. Itoh, S. Takeda et al., "Enhancement of fracture healing by electrical stimulation in the comminuted intraarticular fracture of distal radius," Bio-Medical Materials and Engineering, vol. 23, no. 6, pp. 485-493, 2013.

[14] W. Latham and J. T. C. Lau, "Bone stimulation: a review of its use as an adjunct," Techniques in Orthopaedics, vol. 26, no. 1, pp. 14-21, 2011.
[15] M. Griffin and A. Bayat, "Electrical stimulation in bone healing: critical analysis by evaluating levels of evidence," ePlasty: Open Access Journal of Plastic Surgery, vol. 11, article e34, 2011.

[16] S. Klouche, E. Sariali, and P. Mamoudy, "Total hip arthroplasty revision due to infection: a cost analysis approach," Orthopaedics and Traumatology: Surgery and Research, vol. 96, no. 2, pp. 124-132, 2010.

[17] S. M. Kurtz, E. Lau, H. Watson, J. K. Schmier, and J. Parvizi, "Economic burden of periprosthetic joint infection in the United States," The Journal of Arthroplasty, vol. 27, no. 8, pp. 6165.e1, 2012

[18] C. Vuong and M. Otto, "Staphylococcus epidermidis infections," Microbes and Infection, vol. 4, no. 4, pp. 481-489, 2002.

[19] M. Giladi, Y. Porat, A. Blatt et al., "Microbial growth inhibition by alternating electric fields," Antimicrobial Agents and Chemotherapy, vol. 52, no. 10, pp. 3517-3522, 2008.

[20] J. L. Del Pozo, M. S. Rouse, J. N. Mandrekar, J. M. Steckelberg, and R. Patel, "The electricidal effect: reduction of Staphylococcus and Pseudomonas biofilms by prolonged exposure to low-intensity electrical current," Antimicrobial Agents and Chemotherapy, vol. 53, no. 1, pp. 41-45, 2009.

[21] J. L. Del Pozo, M. S. Rouse, J. N. Mandrekar, M. Fernandez Sampedro, J. M. Steckelberg, and R. Patel, "Effect of electrical current on the activities of antimicrobial agents against Pseudomonas aeruginosa, Staphylococcus aureus, and Staphylococcus epidermidis biofilms," Antimicrobial Agents and Chemotherapy, vol. 53, no. 1, pp. 35-40, 2009.

[22] H. Maadi, M. Haghi, R. Delshad, H. Kangarloo, M. A. Mohammadnezhady, and G. R. Hemmatyar, "Effect of alternating direct currents on Pseudomonas aeruginosa growth in vitro," African Journal of Biotechnology, vol. 9, no. 36, pp. 6373-6379, 2010.

[23] D. Zituni, H. Schütt-Gerowitt, M. Kopp et al., "The growth of Staphylococcus aureus and Escherichia coli in low-direct current electric fields," International Journal of Oral Science, vol. 6, no. 1, pp. 7-14, 2014.

[24] A. Obermeier, F. D. Matl, W. Friess, and A. Stemberger, "Growth inhibition of Staphylococcus aureus induced by low-frequency electric and electromagnetic fields," Bioelectromagnetics, vol. 30, no. 4, pp. 270-279, 2009.

[25] F. D. Matl, A. Obermeier, J. Zlotnyk, W. Friess, A. Stemberger, and R. Burgkart, "Augmentation of antibiotic activity by low-frequency electric and electromagnetic fields examining Staphylococcus aureus in broth media," Bioelectromagnetics, vol. 32, no. 5, pp. 367-377, 2011.

[26] B. Ercan, K. M. Kummer, K. M. Tarquinio, and T. J. Webster, "Decreased Staphylococcus aureus biofilm growth on anodized nanotubular titanium and the effect of electrical stimulation," Acta Biomaterialia, vol. 7, no. 7, pp. 3003-3012, 2011.

[27] M. T. Ehrensberger, M. E. Tobias, S. R. Nodzo et al., "Cathodic voltage-controlled electrical stimulation of titanium implants as treatment for methicillin-resistant Staphylococcus aureus periprosthetic infections," Biomaterials, vol. 41, pp. 97-105, 2015.

[28] S. Nodzo, M. Tobias, L. Hansen et al., "Cathodic electrical stimulation combined with vancomycin enhances treatment of methicillin-resistant Staphylococcus aureus implant-associated infections," Clinical Orthopaedics and Related Research, vol. 473, no. 9, pp. 2856-2864, 2015.

[29] M. R. Asadi and G. Torkaman, "Bacterial inhibition by electrical stimulation," Advances in Wound Care, vol. 3, no. 2, pp. 91-97, 2014. 
[30] E. L. Sandvik, B. R. McLeod, A. E. Parker, and P. S. Stewart, "Direct electric current treatment under physiologic saline conditions kills Staphylococcus epidermidis biofilms via electrolytic generation of hypochlorous acid," PLoS ONE, vol. 8, no. 2, Article ID e55118, 2013.

[31] F. Cardarelli, Materials Handbook, Springer, London, UK, 2nd edition, 2008.

[32] K. Lochner, A. Fritsche, A. Jonitz et al., "The potential role of human osteoblasts for periprosthetic osteolysis following exposure to wear particles," International Journal of Molecular Medicine, vol. 28, no. 6, pp. 1055-1063, 2011.

[33] A. S. Stephens, S. R. Stephens, and N. A. Morrison, "Internal control genes for quantitative RT-PCR expression analysis in mouse osteoblasts, osteoclasts and macrophages," BMC Research Notes, vol. 4, no. 1, article 410, 2011.

[34] P. R. Supronowicz, P. M. Ajayan, K. R. Ullmann, B. P. Arulanandam, D. W. Metzger, and R. Bizios, "Novel current-conducting composite substrates for exposing osteoblasts to alternating current stimulation," Journal of Biomedical Materials Research, vol. 59, no. 3, pp. 499-506, 2002.

[35] C. Windisch, W. Kolb, E. Röhner et al., "Invasive electromagnetic field treatment in osteonecrosis of the femoral head: a prospective cohort study," The Open Orthopaedics Journal, vol. 8, no. 1, pp. 125-129, 2014.

[36] P. C. Grunert, A. Jonitz-Heincke, Y. Su et al., "Establishment of a novel in vitro test setup for electric and magnetic stimulation of human osteoblasts," Cell Biochemistry and Biophysics, vol. 70, no. 2, pp. 805-817, 2014.

[37] M. Abdel-Hady Gepreel and M. Niinomi, "Biocompatibility of Ti-alloys for long-term implantation," Journal of the Mechanical Behavior of Biomedical Materials, vol. 20, pp. 407-415, 2013.

[38] K. Wang, "The use of titanium for medical applications in the USA," Materials Science and Engineering A, vol. 213, no. 1-2, pp. 134-137, 1996.

[39] A. Cornet, D. Muster, and J. H. Jaeger, "Fatigue: corrosion of endoprosthesis titanium alloys," Biomaterials Medical Devices and Artificial Organs, vol. 7, no. 1, pp. 155-167, 1979.

[40] E. Velasco-Ortega, A. Jos, A. M. Cameán, J. Pato-Mourelo, and J. J. Segura-Egea, "In vitro evaluation of cytotoxicity and genotoxicity of a commercial titanium alloy for dental implantology," Mutation Research/Genetic Toxicology and Environmental Mutagenesis, vol. 702, no. 1, pp. 17-23, 2010.

[41] C. Fleck and D. Eifler, "Corrosion, fatigue and corrosion fatigue behaviour of metal implant materials, especially titanium alloys," International Journal of Fatigue, vol. 32, no. 6, pp. 929935, 2010.

[42] D. L. Cochran, P. V. Nummikoski, F. L. Higginbottom, J. S. Hermann, S. R. Makins, and D. Buser, "Evaluation of an endosseous titanium implant with a sandblasted and acidetched surface in the canine mandible: radiographic results," Clinical Oral Implants Research, vol. 7, no. 3, pp. 240-252, 1996.

[43] A. F. Mavrogenis, R. Dimitriou, J. Parvizi, and G. C. Babis, "Biology of implant osseointegration," Journal of Musculoskeletal Neuronal Interactions, vol. 9, no. 2, pp. 61-71, 2009.

[44] R. K. Alla, K. Ginjupalli, N. Upadhya, M. Shammas, R. K. Ravi, and R. Sekhar, "Surface roughness of implants: a review," Trends in Biomaterials and Artificial Organs, vol. 25, no. 3, pp. 112-118, 2011.

[45] K. Suzuki, K. Aoki, and K. Ohya, "Effects of surface roughness of titanium implants on bone remodeling activity of femur in rabbits," Bone, vol. 21, no. 6, pp. 507-514, 1997.
[46] L. Marinucci, S. Balloni, E. Becchetti et al., "Effect of titanium surface roughness on human osteoblast proliferation and gene expression in vitro," International Journal of Oral \& Maxillofacial Implants, vol. 21, no. 5, pp. 719-725, 2006.

[47] K. Kieswetter, Z. Schwartz, T. W. Hummert et al., "Surface roughness modulates the local production of growth factors and cytokines by osteoblast-like MG-63 cells," Journal of Biomedical Materials Research, vol. 32, no. 1, pp. 55-63, 1996.

[48] J. Y. Martin, Z. Schwartz, T. W. Hummert et al., "Effect of titanium surface roughness on proliferation, differentiation, and protein synthesis of human osteoblast-like cells (MG63)," Journal of Biomedical Materials Research, vol. 29, no. 3, pp. 389401, 1995.

[49] M. Hronik-Tupaj, W. L. Rice, M. Cronin-Golomb, D. L. Kaplan, and I. Georgakoudi, "Osteoblastic differentiation and stress response of human mesenchymal stem cells exposed to alternating current electric fields," BioMedical Engineering Online, vol. 10, article 9, 2011.

[50] B. Ercan and T. J. Webster, "The effect of biphasic electrical stimulation on osteoblast function at anodized nanotubular titanium surfaces," Biomaterials, vol. 31, no. 13, pp. 3684-3693, 2010.

[51] R. A. Gittens, R. Olivares-Navarrete, R. Rettew et al., "Electrical polarization of titanium surfaces for the enhancement of osteoblast differentiation," Bioelectromagnetics, vol. 34, no. 8, pp. 599-612, 2013.

[52] B. Hiemer, J. Ziebart, A. Jonitz-Heincke et al., "Magnetically induced electrostimulation of human osteoblasts results in enhanced cell viability and osteogenic differentiation," International Journal of Molecular Medicine, vol. 38, no. 1, pp. 57-64, 2016. 

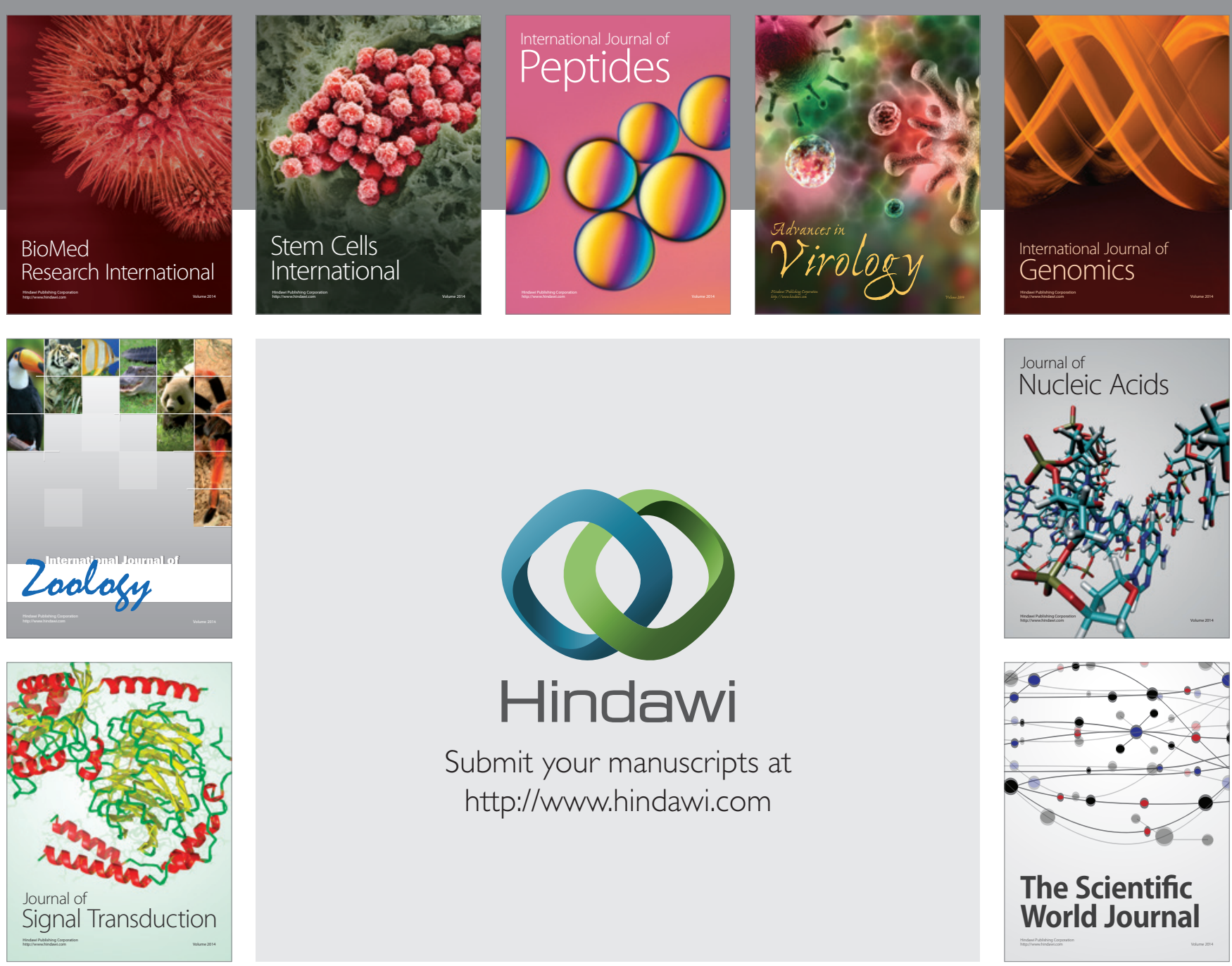

Submit your manuscripts at

http://www.hindawi.com
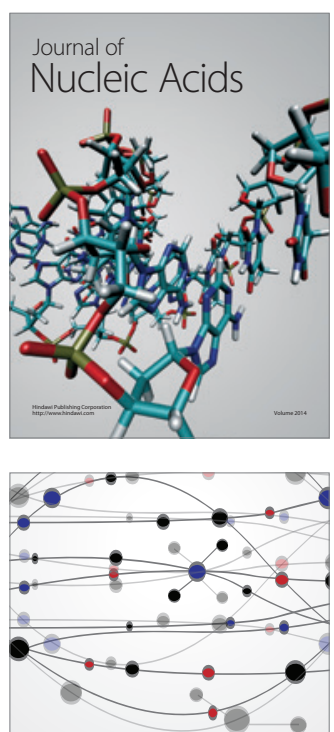

The Scientific World Journal
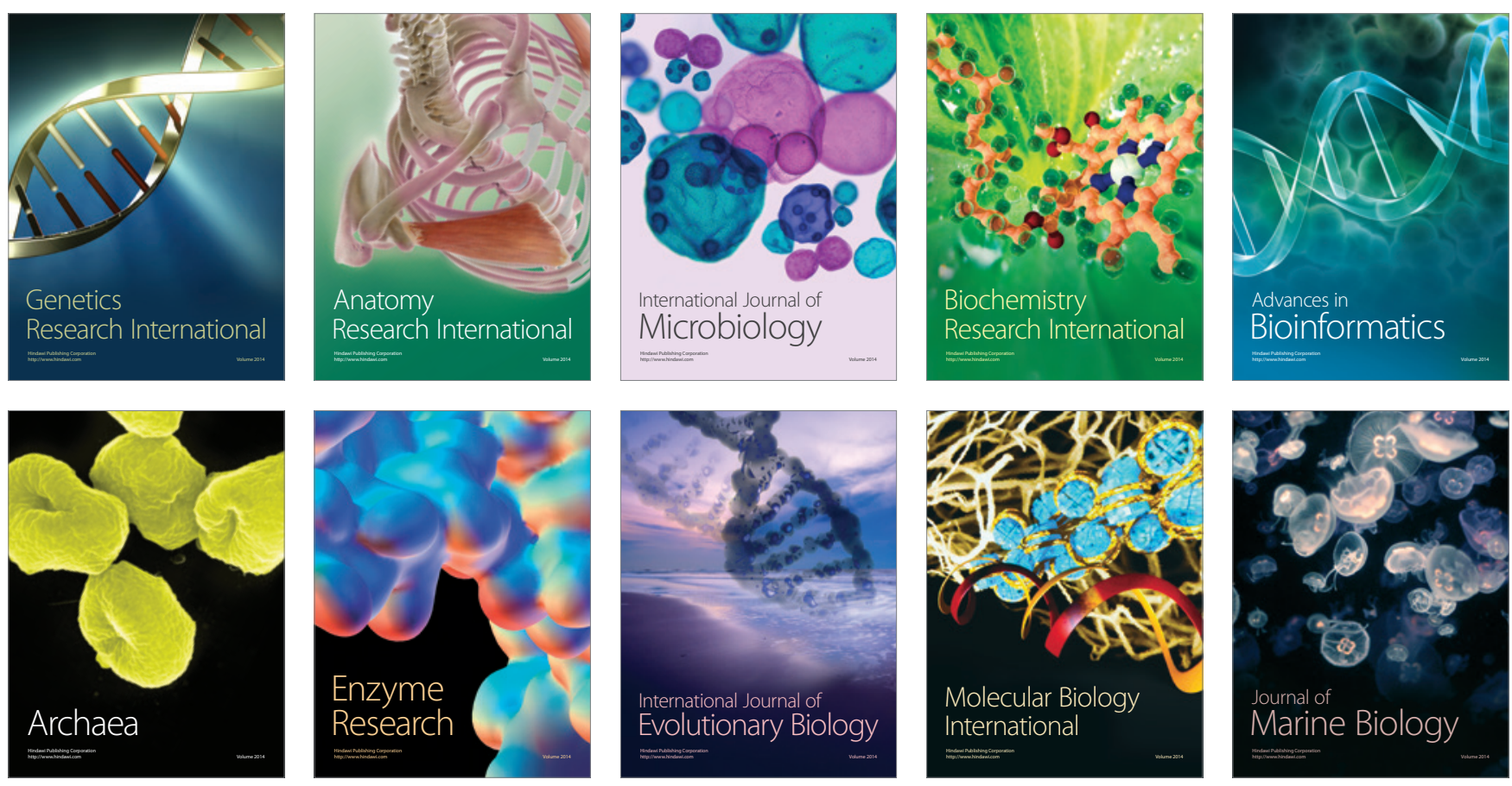